\title{
Impact of Corporate Advertising on Consumers' Attitudes toward Products
}

\author{
Benedikt Spangardt \\ Correspondence: Benedikt Spangardt, University of Würzburg, Media and Business Communication, Os- \\ wald-Külpe-Weg 82, 97074 Würzburg, Germany
}

\author{
Received: February 14, 2016 Accepted: February 16, 2016 Online Published: February 21, 2016 \\ doi:10.11114/bms.v2i1.1394 URL: http://dx.doi.org/10.11114/bms.v2i1.1394
}

\begin{abstract}
Corporate advertising - advertising designed to build and maintain corporate image rather than to promote sales - is becoming increasingly important for many companies. In addition to the questions regarding whether, and, if so, how corporate advertising contributes to the goal of building and maintaining corporate image, one could also ask if it influences other areas of a company. In this study, corporate advertising was assumed to affect consumer attitudes toward company products, even if the advertising promoted the company in general terms but did not feature any products. The results of an online survey involving 408 participants indicate that corporate advertising has a marked effect on consumer attitudes toward company products, and that this effect could be influenced by product involvement.
\end{abstract}

Keywords: corporate advertising, marketing, corporate communications, involvement, heuristics

\section{Introduction}

Corporate advertising has gained increasing importance in recent years. Many companies invest in advertising primarily designed to boost corporate image as opposed to sales. Even large multinational corporations and holdings such as Procter \& Gamble and Unilever are increasingly focusing on brand image (Marshall \& Wise, 2013). This is not a new phenomenon, at least with regard to the Anglo-American market; between 1970 and 1990, a small number of studies were published on this issue (Schumann, Hathcote, \& West, 1991). In the 1980s it was stated that 'corporate advertising has received greater attention over the past decade' (Crane, 1990, p. 31), while in the 1990s, a triennial study conducted by the Association of National Advertisers revealed that between 1995 and 1997, two-thirds of all US-owned companies employed corporate advertising to the sum of approximately US\$16 million (Cardona, 1998). In 2004, corporate advertising generated approximately 11 billion dollars in profit for the advertising industry (Belch \& Belch, 2004). The last notable research review that explicitly discussed corporate advertising was that of Schumann et al. (1991).

As far back as the eighties, Patti and McDonald (1985) predicted that corporate advertising would become more important; however, scientific analysis of this issue remains rare, generally dealing with very specific phenomena. As previously noted, 'the use of corporate advertising [...] has increased, but only limited research has been done to explore the nature of it' (Kim, Haley, \& Koo, 2009, p. 67).

During the past 30 years, research has e.g. examined corporate advertising messages (Ho \& Hallahan, 2004; Hwang, McMillan, \& Lee, 2003), its objectives of influencing corporate image (Haley 1996; Jørgensen \& Isaksson, 2008; Schumann, Hathcote, \& West, 1991), and its effects on perceptions and attitudes (Burgoon, Pfau, \& Birk, 1995; Javalgi, Taylor, Gross, \& Lampman, 1994; Kim \& Choi, 2014; Pashupati, Arpan, \& Nikolaev, 2002; Winters 1986). However, few studies have examined corporate advertising in markets outside the US (Frauscher \& Signitzer, 1991; McLeod \& Kunita, 1994).

Results from studies by Sheinin and Biehal (1999), Gürhan-Canli and Batra (2004), Biehal and Sheinin (2007), Kim, Haley and Lee (2008) and Kim et al. (2009) suggest that there is a relationship between corporate advertising and consumers' attitude toward product ads, product images and products of the same company in general. Corporate advertising seems to have an influence on consumers' attitudes toward products. However, the nature of this influence remains unclear. The aim of this paper is to contribute to its clarification. Therefore, this paper examines whether presenting a corporate ad or not affects consumer's general perception of a product. Furthermore, the influence of product involvement is analyzed.

This paper begins by discussing the term corporate advertising, as a variety of definitions of corporate advertising have been suggested. Then, the theoretical background on the relationship between corporate advertising and consumers' 
attitudes toward products is briefly outlined and leads toward the hypotheses. The remaining part of the paper shows how the hypotheses were tested by means of an online experimental study. Results are presented and discussed at the end.

\subsection{Corporate Advertising}

Corporate advertising comprises a complex set of facets, and is therefore difficult to define in a specific and consistent way (Garbett, 1981, 1983; Kerr, 2003; Schumann et al., 1991). Kerr (2003) uses the term 'corporate advertising' as a matter of course, but in fact the meaning is commonly somewhat unclear. To avoid confusion and provide a clear definition of the term used within the scope of the present study, a short overview of the various forms and definitions of 'corporate advertising' is provided below.

It is difficult to find a common term that describes the phenomenon whereby companies employ advertising not only for their products and services, but also for themselves. Currently, various forms of corporate advertising, including 'institutional advertising', 'image advertising', 'issue advertising', and 'umbrella advertising' exist in parallel and are not sufficiently differentiated one from one another (Crane, 1990; McLeod \& Kunita, 1994; Patti \& MacDonald, 1985).

As mentioned above, a common consensus regarding the definition of 'corporate advertising' is that it is not employed to promote services or products (Garbett, 1983; Rau \& Preble, 1988). Corporate Advertising is also not designed to ask some action on the part of the audience beyond passive approval and a favorable attitude towards the company (Sethi, 1979). Contrary to classical product or consumer advertising, corporate advertising is often referred to as a form of communication designed to influence the 'corporate-social environment' (McLeod \& Kunita, 1994, p. 13). The primary goals of corporate advertising are to build and maintain a specific corporate image (Pashupati et al., 2002; Schumann et al., 1991), as well as a strong reputation (Jørgensen \& Isaaksson, 2008). Corporate advertising also seeks to help companies gain the trust of consumers (Smith, Smith, \& Dunbar, 2014). Corporate advertising can clearly be seen residing at the junction between classical advertising (as part of marketing strategy) and public relations, because notwithstanding the term advertising and the use of paid media space and classical forms of advertising, trust becomes a central tenet. The concept of using communication to build trust towards an organization is well known from research in the field of public relations (Broom, 2012; Ledingham \& Bruning, 1998).

Furthermore, due to its supposed proximity to public relations, corporate advertising is seen as a tool for crisis communication (Kerr, 2003). Previous research in this field by Kim and Choi (2014) suggested that corporate advertising is used when the company is criticized; i.e., when public sentiment regarding the company (or other types of organizations, cf. Ho \& Hallahan, 2004) becomes negative. In this context, previous studies have examined whether corporate advertising can help minimize the damage to a company's brand image and reputation as the result of a crisis, serving as a type of buffer against negative news (Pashupati et al., 2002; Smith et al., 2014; Winters, 1986). Therefore, research on corporate advertising is often conducted using examples of businesses with an increased risk of damage to their public image, such as companies in the energy (oil) sector (Kerr, 2003; Smith et al., 2014; Winters, 1983, 1986) or financial services industries (Bobinski \& Ramirez, 1994; Crane, 1990; Jørgensen \& Isaaksson, 2008).

However, most of these studies share the common belief that corporate advertising is not employed to improve sales. This sets the foundation for the following definition of corporate advertising, which will be employed in the remainder of this paper: Corporate advertising is a planned process of communication designed to convey a certain corporate image to the recipients and intended to create and maintain acceptance, credibility, and trust for and in the company. For these purposes, corporate advertising uses the (classical) means of advertising, and is usually distributed using paid media space. The content of such ads typically involves descriptions and delineations of the self-image and the actions of the company, never for a specific product. If products do appear in the ads, they are not specifically referred to, emphasized, or set in the foreground.

\subsection{Pass-through onto Products}

Although corporate advertising is often described as a type of advertising that does not promote a specific product, the position of this paper is that a corporation cannot be regarded as independent of its products. In most cases, consumers are conscious to some extent of the company and its products, thereby firmly linking the two. Among consumers, knowledge about and attitudes toward a company have been reported to influence their knowledge about and attitudes toward products newly introduced to the market (Brown \& Dacin, 1997).

It is generally assumed that advertising influences stakeholders beyond those who are actually targeted. For example, recruitment advertising can strengthen brands in general, even among individuals who are not potential employees (Collins \& Stevens, 2002; Wilden, Gudergan, \& Lings, 2010). Kerr (2003) reported that a corporate ad campaign by Shell positively affected their product sales, and Rosengren and Bondesson (2014) found that product or consumer advertising can have an impact on other stakeholders such as financial investors or job applicants. Roughly speaking, 
this is the 'reverse' effect of that which the present study aims to explain - the impact of corporate advertising on a particular group of stakeholders, namely consumers.

Consumers retain the knowledge they gain from a corporate ad and integrate it with their knowledge of the company (Homer, 1990; MacKenzie, Lutz, \& Belch, 1986). This would substantially support one of the goals of corporate advertising listed above, which is to build and maintain a positive corporate image (Schumann et al., 1991). Additionally, Kelly and Edwards (1998) have reported that consumers generally prefer image ads over product advertisements. The former were liked better and were considered as more persuasive by the participants.

Similar to brand knowledge, knowledge about a company includes attitudes, opinions, and effects (Garbett, 1981; Keller, 2001; MacKenzie et al., 1986). Each of these factors can influence consumer attitudes toward products; these attitudes result from a combination of spontaneous impressions and knowledge retrieved from memory. Knowledge retrieval is influenced by retrieval cues such as brand names and logos (Keller, 1987; Biehal \& Sheinin, 1998), and this retrieved knowledge can influence new and old attitudes alike (Sheinin \& Biehal, 1999). However, Sheinin and Biehal also assumed that corporate advertising previously seen by consumers affected their reaction to a product presented by that company; therefore, they only examined the effects of corporate advertising on attitudes toward product ads, not the actual product itself, and thus only asked subjects to assess print ads for products after showing them corporate ads.

\subsection{Hypotheses}

These considerations lead to the following question: when a product is presented to consumers, do they assess it differently based on whether they have been shown a corporate ad from the company? This question is the basis for the first hypothesis:

$\mathrm{H}_{1}$ : Consumers who are shown a corporate ad assess a product manufactured by the company in the ad differently than those who are not shown a corporate ad.

As described above, the retrieval of information gained from corporate advertising can be viewed as a heuristic process in terms of the Elaboration Likelihood Model (ELM). According to the ELM, individuals fall back to such a heuristic approach when the strength of elaboration during product assessment is not high (i.e., if it is a low-involvement product for the consumer). If a company places a retrieval cue on a product, it will serve as a peripheral cue during the mental assessment of that product (Petty, Brinol, \& Priester, 2011; Petty \& Cacioppo, 1986), which causes the consumer to regress to the information gained from corporate advertising. These considerations lead to the second hypothesis of this study:

$\mathrm{H}_{2}$ : The effect proposed in $\mathrm{H}_{1}$ is stronger during assessment of a low-involvement product compared with a high-involvement product.

\section{Method}

\subsection{Design}

An online experiment was designed as a $2 \times 2$ between-subject experiment. The participants were recruited through various channels on the Internet and followed a link to an online survey form. After a short introduction, approximately half of the participants were shown a TV spot that included a corporate ad. Within this group, approximately $50 \%$ watched a corporate ad for Samsung, while the other half watched a corporate ad for Nestlé. Neither of the spots featured a specific company product. In fact, both ads contained various statements about the company's general aims, atmosphere, or traditions. Next, the participants were asked to judge a product manufactured by each of the companies. One product ('Smarties', a chocolate confectionery produced by Nestlé) was intended to represent a low-involvement product, while the other product ('Galaxy Tab 3', a tablet computer manufactured by Samsung) was intended to represent a high-involvement product.

Participants in the second group were also asked to assess each of these products, but without having viewed any type of corporate advertising beforehand. The product images were chosen such that the recipients could clearly recognize the logo of the company as a retrieval cue (Keller, 1987; Biehal \& Sheinin, 1998).

The questionnaire was filled in by 613 persons. Participants were randomly assigned to the two groups using survey software ('Unipark' by QuestBack GmbH, Cologne). After excluding 205 cases due to irregularities such as missing information, not completing the questionnaire or taking either too much or not enough time to fill in the questionnaire, a total of 408 cases $\left(61.3 \%\right.$ female; mean age $\left[M_{\text {age }}\right]=27.12$ years, standard deviation $[S D]=12.13$ years $)$ were analyzed. 
Table 1 . The $2 \times 2$ between-subject design used in the present study

\begin{tabular}{|c|c|c|}
\hline & $\begin{array}{l}\text { low involvement product } \\
\text { 'Smarties' }\end{array}$ & $\begin{array}{l}\text { high involvement product } \\
\text { 'Galaxy Tab 3' }\end{array}$ \\
\hline \multirow{3}{*}{$\begin{array}{l}\text { without } \\
\text { corporate advertising }\end{array}$} & control group 1 & control group 2 \\
\hline & (low involvement) & (high involvement) \\
\hline & $N=105$ & $N=105$ \\
\hline \multirow{3}{*}{$\begin{array}{c}\text { with } \\
\text { corporate advertising }\end{array}$} & experimental group 1 (low & experimental group 2 (high \\
\hline & involvement) & involvement) \\
\hline & $N=116$ & $N=82$ \\
\hline
\end{tabular}

\subsection{Measures}

The independent variable 'product involvement' was measured using a scale slightly modified from that used by Zaichowski (1985). Participants were shown a four-point semantic differential with 10 bipolar adjectives (with ' 1 ' representing the negative end of the scale and ' 4 ' representing the positive end). An index was formed using these 10 variables (Cronbach's $\alpha=.91$ ). For a manipulation check to assess whether the two products actually matched the hypothesis of being high- or low-involvement products, differences in involvement were assessed. The tablet computer was shown to be a significantly higher-involvement product $(M=2.76 ; S D=.66)$ than the chocolate confectionery $(M=2.29 ; S D$ $=.58 ; t(371.34)=-7.54 ; p=.00)$.

The dependent variable 'attitude toward the product' was measured using 20 items on a four-point Likert scale from 'completely false' (1) to 'completely true' (4). Items were taken from Benedek and Miner (2002) and complemented with additional items. To achieve dimension reduction, principal factor analysis was conducted on the 20 items. Because we expected the factors not to be completely independent of each other, and orthogonal rotation is not recommended when correlated factors are expected, we conducted the analysis using oblique rotation (direct oblimin) as suggested by Fabrigar, Wegener, MacCallum and Strahan (1999) and Russell (2002). The Kaiser-Meyer-Olkin (KMO) criterion verified the adequacy of the variables in the sample $(K M O=.911$; 'marvelous' according to Hutcheson and Sofroniou, 1999).

Taken together, the four factors listed in Table 2 explain $63.84 \%$ of the variance after rotation. Factor 1 represented the attitude toward the product as 'attractive'. Factor 2 was labeled 'social', Factor 3 'exciting', and Factor 4 'emotional'. The corresponding indices were formed, yielding satisfactory reliabilities as follows: $\alpha_{\text {attractive }}=.83, \alpha_{\text {social }}=.80, \alpha_{\text {exciting }}$ $=.77$ and $\alpha_{\text {emotional }}=.79$.

Table 2. Pattern matrix of a factor analysis for 20 items of attitude towards products (principal axis factoring extraction with oblimin rotation)

\section{Results}

\begin{tabular}{|c|c|c|c|c|}
\hline \multirow{2}{*}{$\begin{array}{l}\text { item } \\
\text { (attitude toward product) }\end{array}$} & \multicolumn{4}{|c|}{ factor } \\
\hline & 1 & 2 & 3 & 4 \\
\hline reliable & .762 & & & \\
\hline high quality & .753 & & & \\
\hline useful & .746 & & & \\
\hline appealing & .567 & & & \\
\hline trustworthy & .562 & & & \\
\hline innovative & .559 & & & \\
\hline sustainable & .465 & & & \\
\hline traditional & & .825 & & \\
\hline family-oriented & & .754 & & \\
\hline familiar & & .621 & & \\
\hline collaborative & & .520 & & \\
\hline fun & & & .845 & \\
\hline exciting & & & .735 & \\
\hline desirable & & & .555 & \\
\hline emotional & & & & -.837 \\
\hline passionate & & & & -.835 \\
\hline creative & & & & -.497 \\
\hline
\end{tabular}

$\mathrm{H}_{1}$ states that participants who are shown a corporate ad will assess a product related to the respective company differently than those who are not exposed to a corporate ad. To test this hypothesis, mean differences between the experimental and control groups were analyzed for each of the four dimensions of attitude toward the relevant product. Significant differences with small to medium effect sizes were found in every dimension; after being exposed to a TV spot that included a corporate ad, participants assessed the product as being significantly more attractive, social, and emotional, and less exciting (Table 3). The considerable mean differences and medium effect sizes in the 'social' and 'emotional' dimensions could be explained based on the content of the TV spots focusing on social living, family, and tradi- 
tion. Without conducting an actual content analysis of the TV spot, it could be stated that the spot induced a quiet and comfortable atmosphere. This could have influenced the attitude toward the product as being less exciting among the members of the control group. However, $\mathrm{H}_{1}$ is considered verified because the predicted effect was found: corporate advertising significantly affects consumer attitudes toward a product manufactured by that company.

Table 3. Differences in attitudes toward products with and without prior exposure to corporate advertising

\begin{tabular}{|c|c|c|c|c|c|c|c|c|}
\hline \multirow{2}{*}{$\begin{array}{l}\text { attitude toward } \\
\text { the product }\end{array}$} & \multicolumn{2}{|c|}{$\begin{array}{c}\text { Group 1 } \\
\text { (with corporate ad) }\end{array}$} & \multicolumn{2}{|c|}{$\begin{array}{c}\text { Group } 2 \\
\text { (without corporate ad) }\end{array}$} & \multirow[b]{2}{*}{$d f$} & \multirow[b]{2}{*}{$t$} & \multirow[b]{2}{*}{$p$} & \multirow[b]{2}{*}{$d$} \\
\hline & $M$ & $S D$ & $M$ & $S D$ & & & & \\
\hline 'attractive' & 2.72 & .64 & 2.60 & .57 & 406 & 1.98 & .048 & .20 \\
\hline 'social' & 2.61 & .82 & 2.33 & .86 & 406 & 3.41 & .001 & .33 \\
\hline 'exciting’ & 2.59 & .71 & 2.78 & .64 & 406 & -2.72 & .007 & .28 \\
\hline 'emotional' & 2.60 & .80 & 2.19 & .68 & 386.11 & 5.49 & $\leq .001$ & .55 \\
\hline
\end{tabular}

Note. $\mathrm{n}_{\text {Group } 1}=198, \mathrm{n}_{\text {Group } 2}=210$; 'Attitude toward the product' was measured on a four-point scale from $1=$ not at all true, to 4 = completely true; $d=$ measure of effect size 'Cohen's d';

$\mathrm{H}_{2}$ stated that differences in attitudes toward products between the experimental and control groups would be stronger under the condition of low- than high-product involvement. This was true for the dependent variables 'attractive' and 'exciting'. While the attitude toward the product showed little variation between the two groups under the condition of high-product involvement, a mean difference was evident under the condition of low-product involvement (cf. Figures 1 and 2).

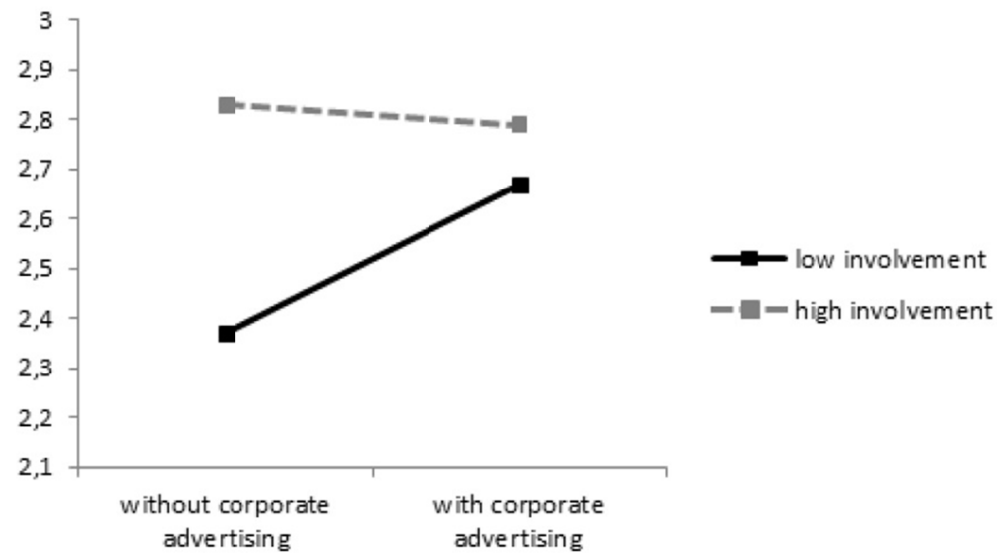

Figure 1. Attitudes toward products viewed as 'attractive': differences based on involvement and presence or absence of corporate advertising.

Note. Vertical axis shows the extent to which participants judged the product as 'attractive' (1-to-4-scale). The interaction effect was significant $\left(F(1,404)=8.66 ; p<0.01\right.$; partial $\left.\eta^{2}=.021\right)$.

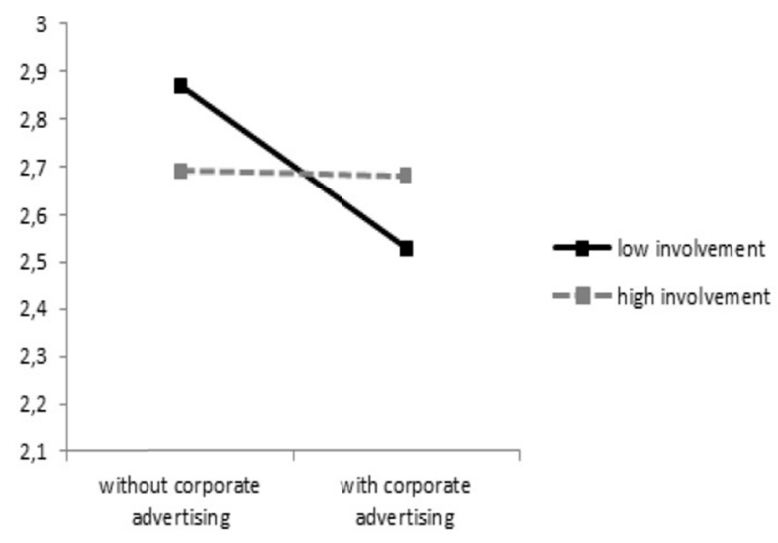

Figure 2. Attitudes toward products viewed as 'exciting': differences based on involvement and presence or absence of corporate advertising.

Note: Vertical axis shows the extent to which participants judged the product as 'exciting' (1-to-4-scale). The interaction effect was significant $\left(F(1,404)=6.15 ; p<0.05 ;\right.$ partial $\left.\eta^{2}=.015\right)$. 
An interaction effect was also found for the dependent variable 'social' $\left(F(1,404)=8.30 ; p<0.01 ;\right.$ partial $\left.\eta^{2}=.020\right)$, although opposite to that expected: a mean difference was evident in the high-involvement group, but the difference was close to zero in the low-involvement group. This unexpected result may reflect the fact that the two products presented to the participants differ in terms of the attitude dimension 'social'. The confectionery is generally seen as a family-oriented product. Perhaps in this case, even if the involvement is low, no heuristics, and hence no knowledge retrieval, are necessary to assess this product in the 'social' dimension. On the other hand, the tablet computer is a somewhat technical and 'cold' product, and is thereby difficult to assess in the 'social' dimension. Even if the product involvement was high, the participants needed heuristics when asked to what extent they considered the tablet as 'social'.

No interaction effects were found for the fourth dimension, 'emotional', and no differences were observed between the low- and high-involvement groups. Apparently, both groups were drawn to the delineated heuristic regardless of their involvement. Similar to what was expounded regarding the 'social' dimension, it was suspected that participants found it difficult to assess products in the 'emotional' dimension. This could be linked to the single items in this category that may not have been completely suitable for the task. Consequently, both the low- and high-involvement groups sought support to assess the product in terms of the 'emotional' dimension and therefore drew knowledge from the TV spots.

\section{Discussion}

While $\mathrm{H}_{1}$ was fully supported, $\mathrm{H}_{2}$ is only partially accepted. Above all, it is clear that corporate advertising affects consumer attitudes toward products manufactured by the company shown in the respective ad. In fact, consistent with the findings of Collins and Stevens (2002), the effects of advertising are not restricted to the target group, which in the case of corporate advertising can be, but is not limited to, the consumer. The present study furthers the work of Sheinin and Biehal (1999) because the participants were asked about their attitudes toward the products as opposed to the product ads.

Consistent with Keller and Edward's (1998) finding that image ads can influence purchase intentions and Kerr's (2003) assumption that a corporate ad campaign can affect sales, mostly positive shifts were found in the experimental group in terms of attitudes toward products. The interpretation that this shift leads to a higher willingness to buy is not far-fetched, but is beyond that supported by the positive effect of the stimulus on the 'attractiveness' dimension. Nevertheless, it must be kept in mind that participants were not asked about their purchase intentions, but rather for their attitudes toward the products. Further studies should examine the effects of corporate ads not only on attitudes, but also on purchase intentions or even concrete purchase decisions.

In line with Biehal and Sheinin (1998) and Biehal and Sheinin (2007) the present results suggest that a variety of factors influence the association between brand knowledge and knowledge drawn from corporate ads. Biehal and Sheinin suggest that the same processes by which these two kinds of knowledge influence each other should be further examined; however, little if any research has been done to explore these effects. This study answered their call for assessment of the role of customer involvement with the product; as a result, the existence of effects that verify $\mathrm{H}_{1}$ was confirmed. In addition, evidence that these effects are influenced by product involvement and therefore by the strength of elaboration was found. This became clear in the course of analyzing the data used to test $\mathrm{H}_{2}$, which assumed the influence of product involvement. Additional influencing factors, including the placement and size of retrieval cues (e.g., brand names and logos), parasocial interactions with and relationships to characters in the TV spot, the period of advertisement exposition, and elapsed time between watching the TV spot and assessing the product, can also be imagined; these should be systematically examined in future studies. In contrast to Biehal and Sheinin (2007), we asked the participants single products instead of a broader product portfolio. This was convenient on the one hand as the two single products differed clearly in terms of product involvement. On the other hand, it makes the generalization of the results harder.

The failure to confirm $\mathrm{H}_{2}$ might reflect the fact that the stimulus had a range of effects on the identified 'attitude' dimensions toward the product. Possible reasons for this, in terms of difficulties in judging the products in certain dimensions, are discussed above. Aside from this, it could be considered a weakness of the study design that even if the TV spots (stimuli) shared similar values, they were inevitably different. Future research should strive to control the content of the stimulus better or to analyze the content of the ads and incorporate the resulting data in the analysis of effects on the various dimensions of attitudes toward the products. Additionally, further research should incorporate the participants' previous knowledge about and attitudes towards the companies. We made sure that the participants did not know the advertisements but did not control for foreknowledge on the products or the companies. Other corporate advertisements or even product messages may have influenced the participants' judgements. As e.g. Sheinin and Biehal (2007) point out, a kind of "product-to-product spillover" (p. 22) may occur when participants are asked to assess a product they did not know until then. This means that participants could rely to their experiences with similar products of the same company (or even to similar products of competitor) as a knowledge source. The random assignment of participants to the groups in this study should have minimized the bias resulting from preexistent knowledge and attitudes but 
still, further research should try to control these factors.

Above all, upcoming research must clarify how trends in attitudes toward the products (i.e., whether they become more negative or more positive, which was not considered in this study), can be affected. A deeper look into the content of the stimulus would also be beneficial.

The study results should not be seen as representative of the general population because it was conducted as an online survey that allowed the participants to choose whether they would complete the questionnaire. In addition, the study design meant that the environment and other external influences that may have affected the participants' reception of the stimulation could not be controlled. These are typical sources of bias in online experiment designs (Groves, 2011; Wright, 2005) and thus need to be taken into account. Conducting a survey using this design was time- and cost-efficient, and resulted in a high number of completed questionnaires compared with an on-site design. It also facilitated the recruitment of participants, especially those for whom the computer and the Internet are key parts of their everyday lives (van Selm \& Jankowski, 2006). The advantages of this study design outweigh the disadvantages, and few difficulties arise as long as the interpretation of the results considers the limitations of the chosen design.

The findings of this study support the general assumption that corporate advertising can influence consumers' attitudes toward a company's products. There is evidence that the product involvement plays a role in the process of assessing a product under the influence of a corporate message. However, as there is no clear finding regarding this role, further research is required. Given the interesting findings of this study and their implications, as well as their limitations, continuing research into the phenomenon of corporate advertising and its effects is ongoing.

\section{References}

Belch, G. E., \& Belch, M. A. (2004). Advertising and promotion: An integrated marketing communications perspective. New York: McGraw-Hill.

Benedek, J., \& Miner, T. (2002). Measuring Desirability: New methods for evaluation in a usability lab setting. Retrieved from: http://www.microsoft.com/usability/UEPostings/DesirabilityToolkit.doc [02-16-16].

Biehal, G. J., \& Sheinin, D. A. (1998). Managing the brand in a corporate advertising environment: A decision-making framework for brand managers. Journal of Advertising, 27(2), 99-110. http://dx.doi.org/10.1080/00913367.1998.10673555

Biehal, G. J., \& Sheinin, D. A. (2007). The influence of corporate messages on the product portfolio. Journal of Marketing, 71(2), 12-25. http://dx.doi.org/10.1509/jmkg.71.2.12

Bobinski, G., \& Ramirez, G. (1994). Advertising to Investors: The Effect of Financial-Relations Advertising on Stock Volume and Price. Journal of Advertising, 23(4), 13-28. http://dx.doi.org/10.1080/00913367.1943.10673456

Broom, G. (2012). Cutlips and Center's Effective Public Relations. New York: Prentice Hall.

Brown, T., \& Dacin, P. (1997). The Company and the Product: Corporate Associations and Consumer Product Responses. Journal of Marketing, 61, 68-84. http://dx.doi.org/10.2307/1252190

Burgoon, M., Pfau, M., \& Birk, T. S. (1995). An Inoculation Theory Explanation for the Effects of Corporate Issue/Advocacy Advertising Campaigns. Communication Research, 22(4), 485-505. http://dx.doi.org/10.1177/009365095022004006

Cardona, M. (1998). Corporate-Ad Budgets at Record High: ANA Survey. Advertising Age, 69(17), 36.

Collins, C., \& Stevens, C. (2002). The relationship between early recruitment related activities and the application decisions of new labor-market entrants: a brand equity approach to recruitment. Journal of Applied Psychology, 87, 1121-1133. http://dx.doi.org/10.1037/0021-9010.87.6.1121

Crane, F. (1990). The Need for Corporate Advertising in the Financial Services Industry: a Case Study Illustration. Journal of Services Marketing, 4(2), 31-37. http://dx.doi.org/10.1108/EUM0000000002509

Fabrigar, L. R., Wegener, D. T., MacCallum, R. C., \& Strahan, E. J. (1999). Evaluating the use of exploratory factor analysis in psychological research. Psychological Methods, 4, 272-299. doi:10.1037/1082-989X.4.3.272

Frauscher, C., \& Signitzer, B. (1991). Unternehmenswerbung - Eine neue Form von Werbung setzt sich durch. [Corporate advertising. A new form of advertising asserts itself.]. Media Perspektiven, 5(1991), 291-296

Garbett, T. F. (1981). Corporate Advertising: The What, the Why, and the How. New York: McGraw-Hill.

Garbett, T. F. (1983). Researching Corporate Avertising. Journal of Advertising Research, 23, 1, 33-37.

Groves, R. (2011). Three Eras of Survey Research. Public Opinion Quarterly, 75(5), 861-871. http://dx.doi.org/10.1093/poq/nfr057 
Gürhan-Canli, Z., \& Batra, R. (2004). When corporate image affects product evaluations: The moderating role of perceived risk. Journal of marketing research, 4l(2), 197-205. http://dx.doi.org/10.1509/jmkr.41.2.197.28667

Haley, E. J. (1996). Exploring the Construct of Organization as Source: Consumers' Understandings of Organizational Sponsorship of Advocacy Advertising. Journal of Advertising, 25(2), 19-36. http://dx.doi.org/10.1080/00913367.1996.10673497

Ho, F. \& Hallahan, K. (2004). Post-earthquake communications in Taiwan: An examination of corporate advertising and strategy motives. Journal of Communication Management, 8(3), 291-306. http://dx.doi.org/10.1108/13632540410807709

Homer, P. (1990). The mediating role of attitude toward the ad. Some additional evidence. Journal of Marketing Research, 27, 78-86. http://dx.doi.org/10.2307/3172553

Hutcheson, G., \& Sofroniou, N. (1999). The multivariate social scientist. London: Sage.

Hwang, J. S., McMillan, S. J., \& Lee, G. (2003). Corporate web sites as advertising: An analysis of function, audience, and message strategy. Journal of Interactive Advertising, 3(2), 10-23. http://dx.doi.org/10.1080/15252019.2003.10722070

Javalgi, R., Taylor, M., Gross, A., \& Lampman, A. (1994). Awareness of Sponsorship and Corporate Image: An Empirical Investigation. Journal of Advertising, 23(4), 47-58.

Jørgensen, P., \& Isaksson, M. (2008). Building credibility in international banking and financial markets: A study of how corporate reputations are managed through image advertising. Corporate Communications, 13, 365-379. http://dx.doi.org/10.1108/13563280810914801

Keller, K. (1987). Memory Factors in Advertising: The Effect of Advertising Retrieval Cues on Brand Evaluations. Journal of Consumer Research, 14, 316-333. http://dx.doi.org/10.1086/209116

Keller, K. (2001). Building customer-based brand equity. Marketing management, 10(2), 14-21.

Kelly, K. J., \& Edwards, R. W. (1998). Image advertisements for alcohol products: Is their appeal associated with adolescents' intention to consume alcohol? Adolescence, 33(129), 47-60.

Kerr, D. (2003). Corporate advertising - does the public care? Admap, 38(7), 32-35.

Kim, S., \& Choi, S. M. (2014). Is Corporate Advertising Effective in a Crisis? The Effects of Crisis Type and Evaluative Tone of News Coverage. Journal of Promotion Management, 20, 97-114. http://dx.doi.org/10.1080/10496491.2013.872216

Kim, S., Haley, E., \& Koo, G. Y. (2009). Comparison of the paths from consumer involvement types to ad responses between corporate advertising and product advertising. Journal of Advertising, 38(3), 67-80. http://dx.doi.org/10.2753/JOA0091-3367380305

Kim, S., Haley, E., \& Lee, Y. J. (2008). Does consumers' product-related involvement matter when it comes to corporate ads? Journal of Current Issues \& Research in Advertising, 30(2), 37-48. http://dx.doi.org/10.1080/10641734.2008.10505246

Ledingham, J., \& Bruning, S. (1998). Relationship management in public relations: dimensions of an organization-public relationship. Public Relations Review, 24(1), 55-65. http://dx.doi.org/10.1016/S0363-8111(98)80020-9

MacKenzie, S., Lutz, R., \& Belch, G. (1986). The Role of Attitude Toward the Ad as a Mediator of Advertising Effectiveness: A Test of Competing Hypotheses. Journal of Marketing Research, 23, 130-143. http://dx.doi.org/10.2307/3151660

Marshall, J., \& Wise, R. (2013). The Resurgence of the Corporate Brand. Advertising Age, retrieved from http://adage.com/article/cmo-strategy/resurgence-corporate-brand/240855/ [02-16-2016]

McLeod, D., \& Kunita, M. (1994). A comparative analysis of the use of corporate advertising in the United States and Japan. International Journal of Advertising, 13, 137-137.

Pashupati, K., Arpan, L., \& Nikolaev, A. (2002). Corporate Advertising as Inoculation Against Negative News: An Experimental Investigation of Efficacy and Presentation Order Effects. Journal of Current Issues and Research in Advertising, 24(2), 1-15. http://dx.doi.org/10.1080/10641734.2002.10505131

Patti, C., \& McDonald, J. (1985). Corporate Advertising: Process, Practices and Perspectives (1970-1989). Journal of Advertising, 14(1), 42-49. http://dx.doi.org/10.1080/00913367.1985.10672929

Petty, R. E., \& Cacioppo, J. T. (1986). The Elaboration Likelihood Model of persuasion. Advances in Experimental 
Social Psychology, 19, 124-205. http://dx.doi.org/10.1016/S0065-2601(08)60214-2

Petty, R. E., Brinol, R., \& Priester, J. (2009). Mass Media Attitude Change. Implications of the Elaboration Likelihood Model of Persuasion. In J. Bryant \& M.B. Oliver, Media Effects. Advances in Theory and Research. New York: Routledge.

Rau, P., \& Preble, J. (1988). Corporate public issue advertising: an analysis of the attitudes of chief executives. International Journal of Advertising, 7(4), 293-306.

Rosengren, S., \& Bondesson, N. (2014). Consumer advertising as a signal of employer attractiveness. International Journal of Advertising, 33(2), 253-269. http://dx.doi.org/10.2501/IJA-33-2-253-269

Russell, D. W. (2002). In search of underlying dimensions: The use (and abuse) of factor analysis. Personality and Social Psychology Bulletin, 28, 1629-1646. http://dx.doi.org/10.1177/014616702237645

Schumann, D., Hathcote, J., \& West, S. (1991). Corporate Advertising in America: A Review of Published Studies On Use, Measurement, and Effectiveness. Journal of Advertising, 20(3), 35-56. http://dx.doi.org/10.1080/00913367.1991.10673346

Sethi, S. P. (1979). Institutional/image advertising and idea/issue advertising as marketing tools: Some public policy issues. Journal of Marketing, 43(1), 68-78.

Sheinin, D. A., \& Biehal, G. J. (1999). Corporate advertising pass-through onto the brand: Some experimental evidence. Marketing Letters, 10(1), 63-74. http://dx.doi.org/10.1023/A:1008087108223

Smith K., Smith, L., \& Dunbar, S. (2014). Using corporate advertising to improve public perception of energy companies. Journal of Strategic Marketing, 22(4), 347-356. http://dx.doi.org/10.1080/0965254X.2013.876080

Van Selm, M., \& Jankowski, N. (2006). Conducting Online Surveys. Quality \& Quantity, 40, 435-456. doi:10.1007/s11135-005-8081-8

Wilden, R., Gudergan, S., \& Lings, I. (2010). Employer branding: strategic implications for staff recruitment. Journal of Marketing Management, 26(1), 56-73. http://dx.doi.org/10.1080/02672570903577091

Winters, L. (1983). Comparing pretesting and posttesting of corporate advertising. Journal of Advertising Research, 23(1), 25-32.

Winters, L. (1986). The Effect of Brand Advertising on Company Image: Implications for Corporate Advertising. Journal of Advertising Research, 26(2), 54-59.

Wright, K. (2005). Researching Internet-Based Populations: Advantages and Disadvantages of Online Survey Research, Online Questionnaire Authoring Software Packages, and Web Survey Services. Journal of Computer - Mediated Communication, 10. http://dx.doi.org/10.1111/j.1083-6101.2005.tb00259.x

Zaichkowsky, J. L. (1985). Measuring the involvement construct. Journal of consumer research, 12, 341-352. http://dx.doi.org/10.1086/208520

\section{(cc) EY}

This work is licensed under a Creative Commons Attribution 3.0 License. 